\title{
Estrogen receptor-associated expression of keratinocyte growth factor and its possible role in the inhibition of apoptosis in human breast cancer
}

\author{
Naóe Tamaru ${ }^{1,2}$, Yoshitaka Hishikawa ${ }^{1}$, Kuniaki Ejima ${ }^{1}$, Naofumi Nagasue $^{3}$, Satoshi Inoue ${ }^{4}$, \\ Masami Muramatsu ${ }^{4}$, Tomayoshi Hayashi ${ }^{2}$ and Takehiko Koji ${ }^{1}$ \\ ${ }^{1}$ Division of Histology and Cell Biology, Department of Developmental and Reconstructive Medicine, \\ Nagasaki University Graduate School of Biomedical Science, Nagasaki, Japan; ${ }^{2}$ Department of Pathology, \\ Nagasaki University Hospital, Nagasaki, Japan; ${ }^{3}$ Second Department of Surgery, Shimane Medical \\ University, Izumo, Japan and ${ }^{4}$ Future Program Research Division, Saitama Medical School, Saitama, Japan
}

\begin{abstract}
Although estrogen is known to play a crucial role in the pathogenesis of breast cancer, the molecular mechanisms underlying the action of estrogen remain elusive. In the present study, we focused on keratinocyte growth factor (KGF) and its receptor (KGFR) in the pathogenesis of breast cancer, as a growth factor mediating estrogen action, since significant roles of KGF were demonstrated in various steroid hormone-dependent tissues. First, using paraffin-embedded specimens from 42 breast cancer patients, we examined expression patterns of KGF and KGFR by both immunohistochemistry using newly generated antibodies and nonradioactive in situ hybridization with T-T dimerized synthetic oligonucleotide probes. We next compared the results with the expression of estrogen receptor (ER) $\alpha$ and $\beta$, proliferative activity and apoptotic frequency (TUNEL staining). Also, the similar approaches were taken to analyze the expression and role of KGF in ERpositive (MCF7, ZR-75-1) and ER-negative (SK-BR-3, MDA-MB-231) human breast cancer cell lines in vitro. In the surgical specimens, KGF was expressed in cancer cells as well as stromal cells in $19 / 42$ cases (45\%), while KGFR was found in cancer cells in $24 / 42$ cases (57\%). The distribution of protein and mRNA in the analysis of both KGF and KGFR expression generally coincided. Moreover, KGF expression was closely associated with the expression of ER $\alpha$, and the coexpression of KGF and KGFR significantly correlated with lower TUNEL index, but not with proliferative activity. In accordance with the in vivo findings, KGF expression was detected only in ER $\alpha$-positive MCF7 and ZR-75-1 cells in vitro. And more importantly, we found the inhibitory effect of KGF upon the induction of apoptosis by anticancer drugs in MCF7 cells. Collectively, our results indicate that ER $\alpha$ may be involved in KGF expression, and that KGF may play antiapoptotic roles, rather than mitogenic, in human breast cancer.

Laboratory Investigation (2004) 84, 1460-1471, advance online publication, 16 August 2004; doi:10.1038/labinvest.3700166
\end{abstract}

Keywords: apoptosis; breast cancer; estrogen receptor; immunohistochemistry; in situ hybridization; keratinocyte growth factor; TUNEL staining

Breast cancer is the most frequent malignant tumor of women in the USA and European countries. In Japan, the frequency of breast cancer has rapidly increased during the last decade, and currently approximately 20000 women develop breast cancer

Correspondence: Professor T Koji, PhD, Division of Histology and Cell Biology, Department of Developmental and Reconstructive Medicine, Nagasaki University Graduate School of Biomedical Science, 1-12-4 Sakamoto, Nagasaki 852-8523, Japan.

E-mail: tkoji@net.nagasaki-u.ac.jp

Received 27 October 2003; revised 9 July 2004; accepted 11 July 2004; published online 16 August 2004 per year. However, our knowledge of the development and progression of breast cancer is still largely limited. The proliferation and differentiation of breast cancer cells are influenced by estrogen,,$^{1-3}$ which exerts its action through binding to estrogen receptor (ER). Currently, ER is categorized into two subtypes, ER $\alpha$ and $\beta$, and both are believed to act as an active transcription factor, which binds to a specific DNA segment such as the estrogen responsive element (ERE) and AP-1 site, to regulate the expression of a variety of genes., ${ }^{4,5}$ The majority of human breast cancer cells express both ER $\alpha$ and ER $\beta .{ }^{6}$ While ER $\alpha$ is regarded as an indicator of 
good prognosis, ${ }^{6}$ the correlation of ER $\beta$ expression with tamoxifen-sensitivity and prognosis is highly controversial. ${ }^{6-8}$

Several locally synthesized polypeptide growth factors and their receptors are known to interact with estrogen in the pathogenesis of breast cancer. For example, expression of transforming growth factor- $\alpha$ is induced by estrogen and stimulates proliferation of breast cancer cells. ${ }^{9,10}$ On the other hand, HER2 (erbB-2), known as a marker of poor prognosis in human breast cancer, ${ }^{11,12}$ is downregulated by estrogen in an ER-dependent fashion. ${ }^{12,13}$ However, the role of growth factors in the pathogenesis of breast cancer, including their interactions with estrogen, is very complicated and largely unclarified. Keratinocyte growth factor (KGF), also known as fibroblast growth factor (FGF)-7, was originally discovered by Rubin et $a l^{14}$ as a unique member of the FGF family. KGF appeared to be synthesized and secreted by stromal cells and to act on epithelial cells specifically through a high-affinity receptor for KGF (KGFR). ${ }^{14-16}$ Therefore, KGF is considered to be a unidirectional paracrine effector that regulates normal epithelial cell proliferation. ${ }^{15}$ In particular, KGF appears to be an essential mediator of steroids in various reproductive organs as andromedin ${ }^{17}$ and progestomedin. ${ }^{18}$ Indeed, KGF mRNA was detected in isolated stromal cells from human breast cancer ${ }^{19,20}$ and was upregulated by estrogen. ${ }^{20}$ However, there was a significant variation in the level of KGF mRNA, and the significance of its expression in breast cancer tissue remains highly controversial. ${ }^{19,20}$ Moreover, KGF is known to have diverse effects, such as inhibition of apoptosis ${ }^{21-23}$ and regulation of cell differentiation. ${ }^{24-26}$ To help clarify these issues, it is desirable to localize KGF and KGFR at a cellular level in tissue sections of human breast cancer. Although KGF mRNA expression in ruminant mammary gland was previously detected by in situ hybridization using autoradiography, ${ }^{27}$ there have been no reports on immunohistochemical analysis of KGF and KGFR expression in human breast cancer tissue. Considering that the state of mRNA preservation in human surgical specimens can vary considerably, ${ }^{28}$ the analysis of protein expression by immunohistochemistry might yield more convincing information. However, mainly because of the lack of reliable antibodies for KGF and KGFR, studies of KGF and KGFR proteins have been limited.

The present study was designed to assess the significance of KGF and KGFR expression in the pathogenesis of human breast cancer. For this purpose, we localized KGF and KGFR in surgical specimens of human breast cancer using newly prepared antibodies for them. Furthermore, expression of KGF and KGFR was examined at the mRNA level by in situ hybridization. We then compared the KGF and/or KGFR expression with ER $\alpha$ and $\beta$ expression, proliferative activity, and the frequency of apoptosis. We also investigated the association between ERs and KGF expressions and the effect of KGF on the induction of apoptosis in breast cancer cells in vitro. As a result, in surgical specimens, KGF and KGFR were detected in cancer cells and KGF expression was tightly associated with ER $\alpha$ expression. Moreover, coexpression of KGF and KGFR significantly correlated with lower frequency of apoptosis in vivo. In addition, we detected KGF expression only in ER $\alpha$-positive breast cell lines, but not in ER $\alpha$-negative ones. Also, it was found that KGF significantly decreased the frequency of apoptotic cells induced by anticancer drugs in MCF7 cells. These results indicate that KGF expression in breast cancer cells may depend upon the presence of ER $\alpha$, and that KGF may play an inhibitory role in the induction of breast cell apoptosis in an autocrine and/or paracrine manner.

\section{Materials and methods}

\section{Biochemicals and Chemicals}

Paraformaldehyde was purchased from Merck (Darmstadt, Germany). 3,3'-diaminobenzidine/ $4 \mathrm{HCl}$ (DAB) and ethylenediaminetetraacetic acid was purchased from Dojin Laboratories (Kumamoto, Japan). Mixed-bed resin (AG501-X8 (D) Resin 20-50 mesh) was purchased from Bio-Rad Laboratories (Tokyo, Japan). Proteinase K, bovine serum albumin (BSA, minimum 98\%, electrophoresis), yeast transfer RNA (type X-SA), salmon testis DNA, dextran sulfate, polyadenylic acid, heparin, Brij 35, Triton X100, 3-aminopropyltriethoxysilane, $17 \beta$-estradiol, cyclophosphamide, and 5-fluorouracil were purchased from Sigma Chemical Co. (St Louis, MO, USA). Formamide (nuclease and protease free) was purchased from Nacalai Tesque (Kyoto, Japan). Biotin-16-dUTP and terminal deoxynucleotidyl transferase (TdT) were from Roche (Mannheim, Germany). RPMI 1640 was from Invitrogen (Carlsbad, CA, USA). Dextran-coated charcoal-treated fetal bovine serum was from ThermoTrace (Melbourne, Australia). Penicillin potassium and streptomycin sulfate were purchased from Meiji, Ltd. (Tokyo, Japan). Recombinant human KGF was from Peprotech (London, UK). Hoechst 33342 dye was from Calbiochem (La Jolla, CA, USA). All other reagents used in this study were purchased from Wako Pure Chemicals (Osaka, Japan) and were of analytical grade.

\section{Antibodies for KGF and KGFR}

Polyclonal antibodies against KGF and KGFR were prepared by immunization of rabbits against synthetic peptides in cooperation with Nichirei Co. (Tokyo, Japan) as previously described..$^{29}$ For immunohistochemical analysis, anti-KGF antibody 
( $5 \mu \mathrm{g} / \mathrm{ml}$ ) and anti-KGFR antisera (1:600) were used to identify KGF or KGFR expression, respectively, which yielded the highest signal/noise ratio in paraffin-embedded sections of human breast cancer tissues.

\section{Other Antibodies}

A mouse monoclonal antibody against human ER $\alpha$ $(0.3 \mu \mathrm{g} / \mathrm{ml})$ was purchased from DAKO (Glostrup, Denmark). A mouse monoclonal antibody against human Ki-67 $(0.5 \mu \mathrm{g} / \mathrm{ml})$ was purchased from Immunotech (Marseille, France). Rabbit anti-human ER $\beta$ antiserum (1:400) was generated as previously described $^{30,31}$ and kindly provided by Dr Muramatsu (Future Program Research Division, Saitama Medical School). Horseradish peroxidase (HRP)-conjugated goat anti-rabbit IgG F (ab)' (1:200) was purchased from MBL (Nagoya, Japan). HRP-goat anti-mouse IgG F (ab)' (1:200) was purchased from Chemicon International (Temecula, CA, USA). HRPmouse anti-T-T antibody (1:80) was obtained from Kyowa Medex (Shizuoka, Japan). HRP-goat antibiotin antibody (1:100) was from Vector Laboratories (Burlingame, CA, USA). Normal goat IgG, normal rabbit IgG, and normal mouse IgG were from Sigma Chemical Co. Normal goat serum and normal rabbit serum were purchased from DAKO.

\section{Tissue Collection and Preparation}

In all, 42 cases of human breast cancer tissues were surgically resected from 1998 to 2001 and diagnosed histologically as carcinoma. Totally, 36 cases were invasive ductal carcinoma, six cases were invasive lobular carcinoma. All patients were female, the average age was $55.7 \pm 13.9$ years, and did not have preoperative tamoxifen treatment. All patients or their next of kin provided informed consent for participation in the clinical study. The tissues were fixed with $4 \%$ paraformaldehyde in PBS and embedded in paraffin. Serial sections were cut at $5 \mu \mathrm{m}$ thickness and then placed onto 3-aminopropyltriethoxysilane-coated glass slides.

\section{Cell Culture}

MCF7, ZR-75-1 and SK-BR-3 were obtained from Cell Resource Center for Biomedical Research Institute of Development, Aging and Cancer, Tohoku University (Sendai, Japan). MDA-MB-231 was purchased from ATCC (Manassas, VA, USA). For the analysis of KGF expression, cells were incubated for 1 week in phenol-red free RPMI 1640 medium, supplemented with $100 \mathrm{U} / \mathrm{ml}$ penicillin potassium, $100 \mu \mathrm{g} / \mathrm{ml}$ streptomycin sulfate, and $10 \%$ dextrancoated charcoal-treated fetal bovine serum at $37^{\circ} \mathrm{C}$ and $5 \% \mathrm{CO}_{2}$. The cells were further incubated in the chamber slides (Lab-Tek, Nalge Nunc International,
Naperville, IL, USA) in the absence or presence of $10 \mathrm{nM} 17 \beta$-estradiol for 2 more days. After fixation with $4 \%$ paraformaldehyde in PBS for $10 \mathrm{~min}$ at RT, the slides were subjected to enzyme immunohistochemistry. For the analysis of the antiapoptotic effect of KGF, the cells were incubated for 1 day in RPMI 1640 medium supplemented with the antibiotics and $0.1 \%$ dextran-coated charcoaltreated fetal bovine serum at $37^{\circ} \mathrm{C}$ and $5 \%$ $\mathrm{CO}_{2}$. Then $25 \mu \mathrm{g} / \mathrm{ml}$ 5-fluorouracil or $500 \mu \mathrm{g} / \mathrm{ml}$ cyclophosphamide were added with or without $10 \mathrm{ng} / \mathrm{ml}$ recombinant human KGF and further incubated for 2 days. After fixation with $4 \%$ paraformaldehyde in PBS, the staining with Hoechst 33342 was performed and the frequency of cells with nuclear fragmentation as an indicator of apoptosis was calculated. ${ }^{32}$

\section{Immunohistochemistry}

Enzyme immunohistochemistry was performed to examine the expression of KGF, KGFR, ER $\alpha$, ER $\beta$, and Ki-67 in breast cancer tissue. Paraffin sections of breast cancer were deparaffinized with toluene and rehydrated with serially graded ethanol solutions. For KGFR, the sections were immersed in $0.2 \%$ Triton X-100 in PBS for 10 min at room temperature (RT). The sections were autoclaved at $121^{\circ} \mathrm{C}$ for 15 min (for ER $\alpha$ and Ki-67) or microwaved at $95^{\circ} \mathrm{C}$ for $20 \mathrm{~min}$ (for ER $\beta$ ) in $10 \mathrm{mM}$ citrate buffer (pH 6.0). After inactivation of endogenous peroxidase activity with $0.3 \% \mathrm{H}_{2} \mathrm{O}_{2}$ in methanol for $15 \mathrm{~min}$ at $\mathrm{RT}$, the sections were preincubated with blocking solution for $1 \mathrm{~h}$ at RT. For KGFR and ER $\beta, 10 \%$ normal goat serum and 1\% BSA in PBS was used as a blocking solution. For the others, $500 \mu \mathrm{g} / \mathrm{ml}$ normal goat IgG and $1 \%$ BSA in PBS was used. The sections were then incubated with the first antibodies for $2 \mathrm{~h}$ (KGF and KGFR) or overnight (ER $\alpha$, ER $\beta$, and Ki-67) at RT. After incubation, slides were washed 3 times with $0.075 \%$ Brij 35 in PBS. Then sections were reacted with HRP-goat anti-rabbit IgG (1:200) or HRP-goat anti-mouse IgG (1:200) for $1 \mathrm{~h}$ at RT and washed 3 times with $0.075 \%$ Brij 35 in PBS. HRP sites were visualized with $\mathrm{H}_{2} \mathrm{O}_{2}$ and DAB solution ${ }^{33}$ or $\mathrm{H}_{2} \mathrm{O}_{2}$ and $\mathrm{DAB}$ in the presence of nickel and cobalt ions. ${ }^{34}$ As a negative control, normal rabbit IgG, normal rabbit serum, or normal mouse IgG was used instead of the first antibody in each run. For colocalization of ERs and KGF, the sections were stained with anti-KGF antibody according to the protocol described above, and HRP sites were visualized with $\mathrm{H}_{2} \mathrm{O}_{2}$ and DAB solution. Then the sections were immersed in PBS and autoclaved in $10 \mathrm{mM}$ citrate buffer ( $\mathrm{pH} \mathrm{6.0)}$ ) for $15 \mathrm{~min}$ at $121^{\circ} \mathrm{C}$ for $15 \mathrm{~min}$. The sections were immersed in $0.1 \mathrm{M}$ glycine-HCl buffer (pH 2.2) for 30 min 3 times, and rinsed with Milli-Q water once and immersed in PBS. Then the sections were stained with anti-ER antibody, as described above. HRP sites were 
visualized with $\mathrm{H}_{2} \mathrm{O}_{2}$ and 4-chloro-1-naphthol solution. $^{35}$

\section{Probes and Labeling}

Sense and antisense oligo-DNA sequences corresponding to nucleotides No. 648-683 of the human KGF cDNA sequence ${ }^{15}$ and nucleotides No. 1388-1432 of the human KGFR CDNA $^{16}$ were synthesized on a DNA synthesizer. These 36- and 45-base oligo-DNAs were added with two repeats of adenine-thymine-thymine at the $5^{\prime}$ ends, and two or three repeats of it at the $3^{\prime}$ ends of 36-base oligo-DNAs and 45-base oligo-DNAs, respectively, for thymine-thymine (T-T) dimers. ${ }^{36}$ We conducted a computer-assisted search (GenBank nucleic acid sequence database Release 129) of the above KGF and KGFR oligo-DNA sequences (without adenine-thymine-thymine repeats) and found $100 \%$ homology with those mRNA sequences. These KGF and KGFR oligo-DNAs were haptenized by introducing $\mathrm{T}-\mathrm{T}$ dimers by $12000 \mathrm{~J} / \mathrm{m}^{2}$ ultraviolet irradiation, as described previously. ${ }^{36,37}$ We performed preliminary immunodetection and dot-blot hybridization using KGF and KGFR probes as detailed previously, ${ }^{37,38}$ and these results indicated that antisense probes were specific and had adequate sensitivity to be useful for in situ hybridization.

\section{In Situ Hybridization}

In situ hybridization was performed as described previously. ${ }^{18}$ Briefly, paraffin sections of breast cancer were deparaffinized with toluene and rehydrated using serially graded ethanol solutions. The slides were treated with $0.2 \mathrm{~N} \mathrm{HCl}$ for $20 \mathrm{~min}, 0.2 \%$ Triton X-100 in PBS for $10 \mathrm{~min}$, and proteinase $\mathrm{K}$ $\left(25 \mu \mathrm{g} / \mathrm{ml}, 37^{\circ} \mathrm{C}\right.$, for $\left.15 \mathrm{~min}\right)$, successively. After the slides were postfixed with $4 \%$ paraformaldehyde in PBS, they were immersed twice in $2 \mathrm{mg} / \mathrm{ml}$ glycine in PBS for $15 \mathrm{~min}$. Hybridization was carried out at $37^{\circ} \mathrm{C}$ for $\mathrm{KGF}$ and $42^{\circ} \mathrm{C}$ for KGFR overnight in a medium containing $10 \mathrm{mM}$ Tris-HCl (pH 7.4), $1 \mathrm{mM}$ ethylenediaminetetraacetic acid, $0.6 \mathrm{M} \mathrm{NaCl}, 1 \times$ Denhardt's solution, $250 \mu \mathrm{g} / \mathrm{ml}$ yeast transfer RNA, $125 \mu \mathrm{g} / \mathrm{ml}$ salmon testis DNA, $10 \%$ dextran sulfate, $200 \mathrm{U} / \mathrm{ml}$ heparin, $10 \mu \mathrm{g} / \mathrm{ml}$ polyadenylic acid potassium salt, $40 \%$ deionized formamide, and $2 \mu \mathrm{g} / \mathrm{ml}$ $\mathrm{T}-\mathrm{T}$ dimerized KGF probe or T-T dimerized KGFR probe. After hybridization, the slides were washed 3 times with $2 \times$ SSC $/ 50 \%$ formamide/ $0.075 \%$ Brij 35 at $37^{\circ} \mathrm{C}$, twice with $0.5 \times \mathrm{SSC} / 50 \%$ formamide/ $0.075 \%$ Brij 35 at $37^{\circ} \mathrm{C}$ for $1 \mathrm{~h}$ each, and finally washed twice with $2 \times$ SSC at RT for $15 \mathrm{~min}$. The slides were subjected to enzyme immunohistochemistry. After incubation with blocking solution $(5 \%$ BSA, $0.3 \mathrm{M} \mathrm{NaCl}, 100 \mu \mathrm{g} / \mathrm{ml}$ salmon testis DNA, $100 \mu \mathrm{g} / \mathrm{ml}$ yeast transfer RNA, and $500 \mu \mathrm{g} / \mathrm{ml}$ normal mouse IgG in PBS) for $1 \mathrm{~h}$ at RT, the slides were reacted overnight with HRP-mouse anti-T-T antibody (1:80) at RT. After washing with $0.075 \%$ Brij 35 in PBS, visualization of HRP sites was performed with $\mathrm{H}_{2} \mathrm{O}_{2}$ and $\mathrm{DAB}$ in the presence of nickel and cobalt ions, according to the method of Adams. ${ }^{34}$ Positive cells were evaluated based on the staining density over the level of staining with the sense probe using an image analyzer (DAB system; Carl Zeiss, Göttingen, Germany). To confirm the specificity of mRNA signals, a variety of control experiments were conducted. In every run, sense probe was used as a negative control. To evaluate the level of hybridizable RNAs in tissue sections, a 28S rRNA probe was used as a positive control in every case. ${ }^{28}$ Furthermore, some sections were hybridized with antisense probe in the presence of an excess amount of unlabeled antisense or unlabeled sense probe to provide definitive evidence for the sequence specificity of the signal as described previously in detail. ${ }^{38}$

\section{TUNEL Staining}

To analyze internucleosomal DNA fragmentation as a hallmark of apoptosis, TUNEL was carried out according to the method of Gavrieli et $a l^{39}$ with a slight modification. Briefly, the sections were deparaffinized with toluene and rehydrated in serially graded ethanol solutions. After washing with PBS, the sections were treated with proteinase $\mathrm{K}(0.1 \mu \mathrm{g} /$ $\mathrm{ml}$, for $15 \mathrm{~min}$ at $37^{\circ} \mathrm{C}$ ) and rinsed once with distilled water. The sections were incubated with $1 \times$ TdT buffer $(25 \mathrm{mM}$ Tris-HCl buffer, $\mathrm{pH}$ 6.6, containing $0.2 \mathrm{M}$ potassium cacodylate and $0.25 \mathrm{mg} / \mathrm{ml}$ BSA) alone for $30 \mathrm{~min}$ at RT. The sections were then reacted with $200 \mathrm{U} / \mathrm{ml}$ TdT dissolved in TdT buffer supplemented with $5 \mu \mathrm{M}$ biotin-16-dUTP, $20 \mu \mathrm{M}$ dATP, $1.5 \mathrm{mM} \mathrm{CoCl}_{2}$, and $0.1 \mathrm{mM}$ dithiothreitol for $90 \mathrm{~min}$ at $37^{\circ} \mathrm{C}$. The reaction was terminated by washing with $50 \mathrm{mM}$ Tris-HCl buffer (pH 7.4) and endogenous peroxidase activity was inhibited by immersing the slides in $0.3 \% \mathrm{H}_{2} \mathrm{O}_{2}$ in methanol for $15 \mathrm{~min}$ at RT. After incubation with $500 \mu \mathrm{g} / \mathrm{ml}$ normal goat IgG in $5 \%$ BSA in PBS for $1 \mathrm{~h}$ at RT, the sections were reacted with HRP-goat anti-biotin antibody (1:100, diluted with 5\% BSA in PBS) overnight at RT. After washing with $0.075 \%$ Brij 35 in PBS, the HRP sites were visualized with $\mathrm{H}_{2} \mathrm{O}_{2}$ and $\mathrm{DAB}$ in the presence of nickel and cobalt ions according to the method of Adams. ${ }^{34}$ As a negative control, some sections were subjected to reaction without TdT.

\section{Quantitative Analysis}

The results of immunohistochemistry for KGF, KGFR, Ki-67, ER $\alpha$, and ER $\beta$ were graded as positive or negative, compared with the staining with $\operatorname{IgG}$ or serum of normal rabbit or mouse. For quantitative analysis, more than 2000 cancer cells were counted 
in random fields at $\times 400$ magnification, and the number of Ki-67-positive cancer cells was expressed as a percentage of positive cells per total number of counted cancer cells (Ki-67 labeling index (LI); mean \pm s.d.). The percentage of apoptotic cells (TUNEL-positive cells or cells with nuclear fragmentation) was calculated in the same manner as for the Ki-67 LI.

\section{Statistical Analysis}

All data for Ki-67 LI and frequency of apoptosis (TUNEL index or frequency of cells with nuclear fragmentation) were expressed as mean \pm s.d. Differences in Ki-67 LI or frequency of apoptosis were examined for statistical significance using the unpaired Student's $t$-test. Correlation between ER
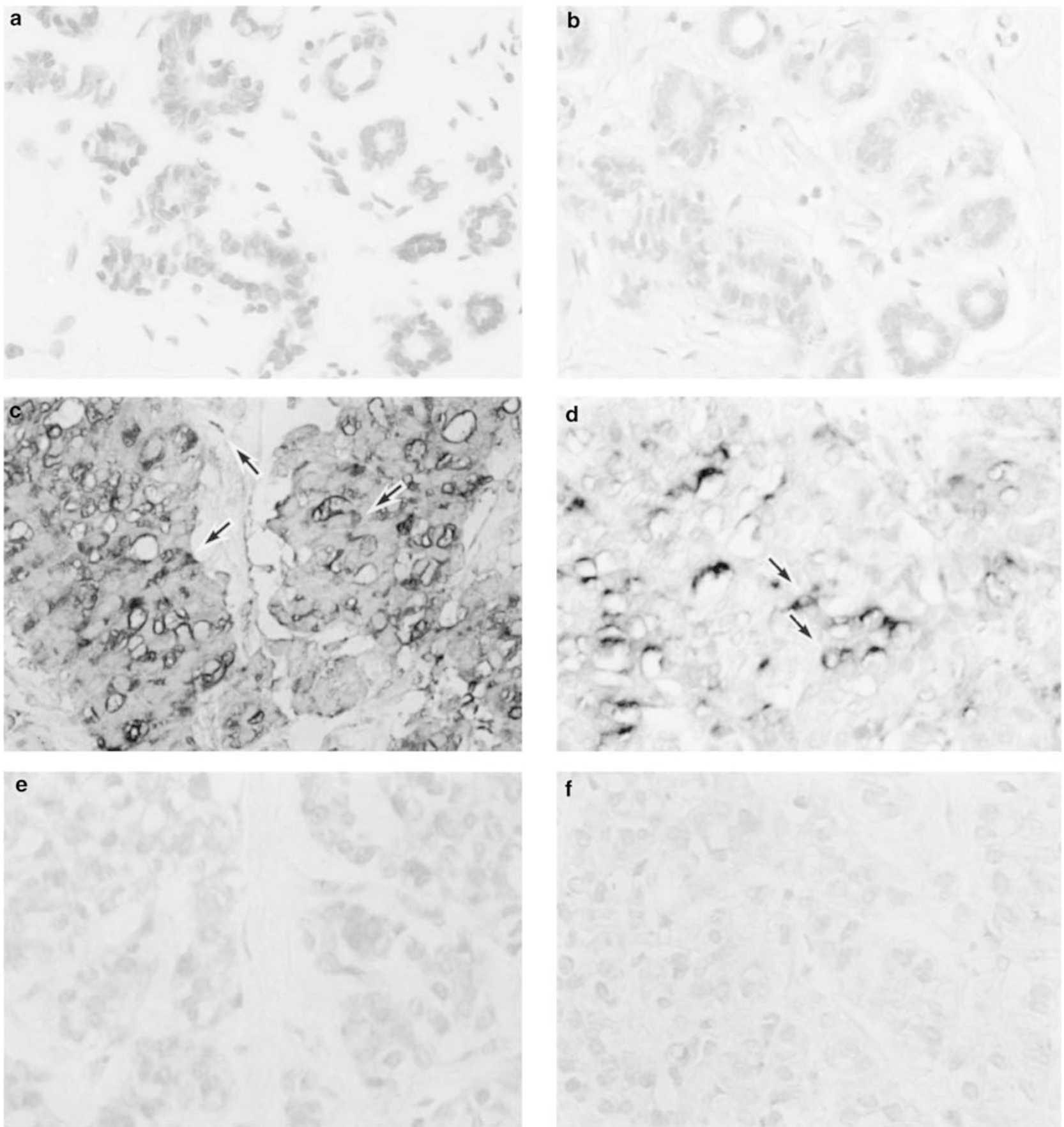

f

Figure 1 Immunohistochemical detection of KGF and KGFR in paraffin sections of normal breast tissue (a, b) and breast cancer (c-f). (a) KGF was not detected in normal breast tissue. (b) KGFR was not detected in normal breast tissue. (c) KGF-positive cells were detected in the tumor nest and in the stroma. (d) KGFR-positive cells were found in the tumor nest. (e) Normal rabbit IgG was used instead of antiKGF antibody. (f) Normal rabbit serum was used instead of anti-KGFR antibody. Arrows=positive cells. Magnification, $\times 100$. 
expression and KGF and/or KGFR expression was examined using $\chi^{2}$ analysis. A $P$-value of less than 0.05 denoted the presence of a statistically significant difference. All analyses were performed with a statistical software package (StatView, version J 5.0; Abacus Concepts, Berkeley, CA, USA).

\section{Results}

\section{Localization of KGF and KGFR in Normal Breast Tissue and Breast Cancer}

KGF (Figure 1a) and KGFR (Figure 1b) were not detected by immunohistochemistry in normal breast tissue. In breast cancer tissue, however, KGF protein was detected in the cytoplasm of cancer cells and stromal cells (Figures 1c and 2a). On the other hand, KGFR was exclusively detected in the plasma membrane and cytoplasm of cancer cells (Figures $1 \mathrm{~d}$ and $2 \mathrm{f}$ ). When sections were reacted with normal rabbit IgG or serum, respectively, instead of the first antibody, no staining was found (Figure 1e and f).

To confirm the expression of KGF and KGFR mRNAs in breast cancer, we performed in situ hybridization. RNA preservation in all specimens was evaluated by methyl green/pyronin Y staining, ${ }^{40}$ and 23 cases with well-preserved RNA were selected for in situ hybridization. As shown in Figure 2, KGF mRNA was detected in the cytoplasm of cancer cells and stromal cells (Figure $2 \mathrm{~b}$ and $\mathrm{c}$ ), which was consistent with the results of immunohistochemistry (Figure 2a). KGFR mRNA was detected in the cytoplasm of cancer cells (Figure 2g and h), and the distribution of KGFR mRNA generally coincided with that of KGFR protein (Figure $2 \mathrm{f}-\mathrm{h}$ ). To verify the specificity of the KGF and KGFR mRNA signals, we conducted various control experiments. When hybridized with KGF (Figure 2d) and KGFR (Figure $2 \mathrm{i})$ sense probes, the staining was markedly reduced compared to that with KGF and KGFR antisense probes. Similarly, when adjacent sections were hybridized with KGF and KGFR antisense probes in the presence of a 100-fold excess amount of unlabeled corresponding antisense oligo-DNA, KGF and KGFR mRNA signal was markedly decreased (Figure 2e and j). In the present study, 19 of $42(45 \%)$ breast cancers expressed KGF protein in cancer cells and/or stromal cells. The number of KGFR-positive cases was 24 of $42(57 \%)$. In total, 10 cases $(24 \%)$ were KGF- and KGFR-negative, 13 cases (31\%) were KGF-negative but KGFR-positive, eight cases (19\%) were KGF-positive but KGFR-negative, and 11 cases (26\%) were both KGF- and KGFR-positive.

\section{Correlation between ER Expression and KGF and/or KGFR Expression}

We examined the expression of ER $\alpha$ and/or $\beta$ and their correlation with KGF and KGFR expression in breast cancer. ER $\alpha$ was detected in the nuclei of cancer cells in 29 of 42 (69\%) cases (Figure 3a). ER $\beta$ was detected in the nuclei of cancer cells in 36 of 42 $(86 \%)$ cases (Figure 3b). In total, two cases were both ER $\alpha$ - and $\beta$-negative, 11 cases were ER $\alpha$-negative, but ER $\beta$-positive, four cases were ER $\alpha$-positive, but
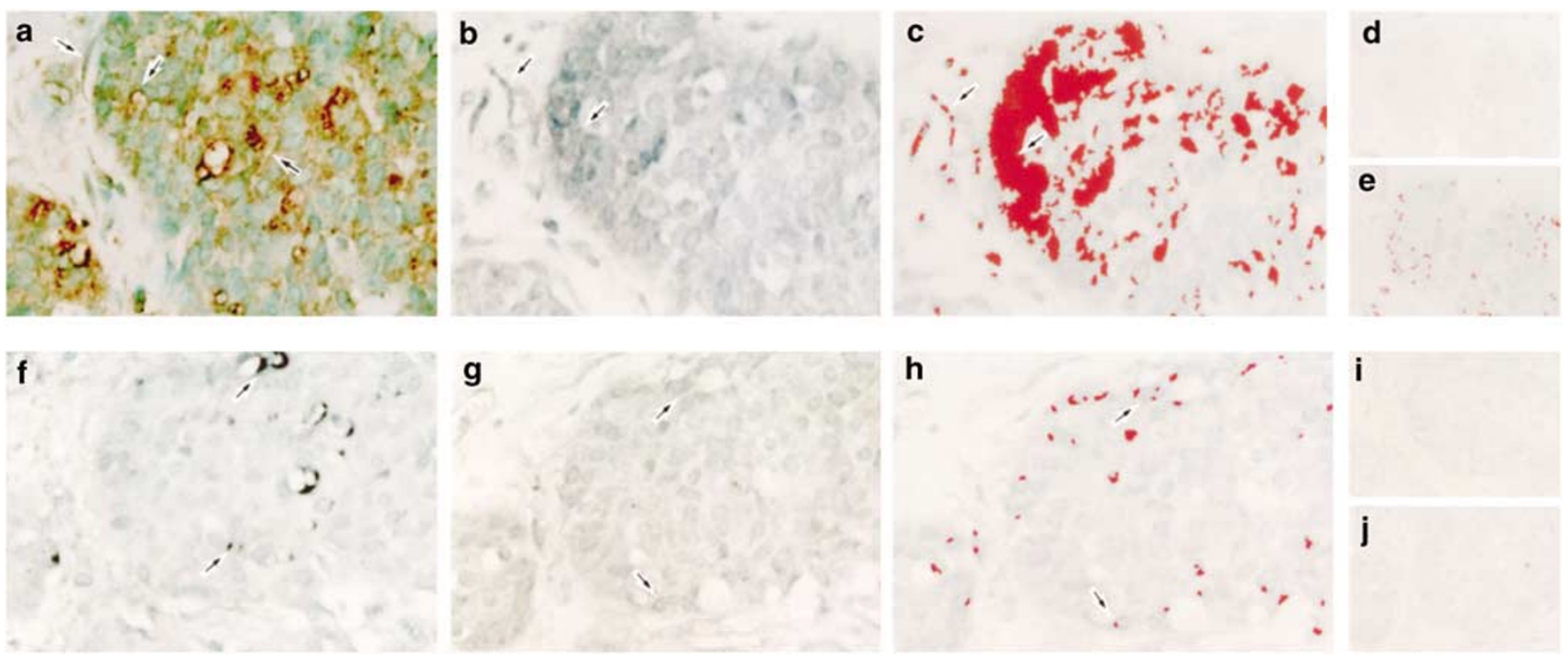

Figure 2 Immunohistochemistry and in situ hybridization for KGF and KGFR in breast cancer tissue. (a) Immunohistochemistry for KGF. KGF-positive cells were found in the tumor nest and in the stroma. (b) Section hybridized with KGF antisense probe. (c) Section hybridized with KGF antisense probe (the same section as (b)) was subjected to an image analyzer. The red color was assigned to positive cells. (d) Section hybridized with KGF sense probe. (e) Section hybridized with KGF antisense probe in the presence of an excess amount of unlabeled antisense probe. Red-colored positive cells were obviously fewer compared with (c). (f) Immunohistochemistry for KGFR. (g) Section hybridized with KGFR antisense probe. (h) Section hybridized with KGFR antisense probe (the same section as (g) was subjected to an image analyzer. The red color was assigned to positive cells. (i) Section hybridized with KGFR sense probe. (j) Section hybridized with KGFR antisense probe in the presence of an excess amount of unlabeled antisense probe. No positive cells were found. Arrows $=$ positive cells. Magnification, $\times 100$. 

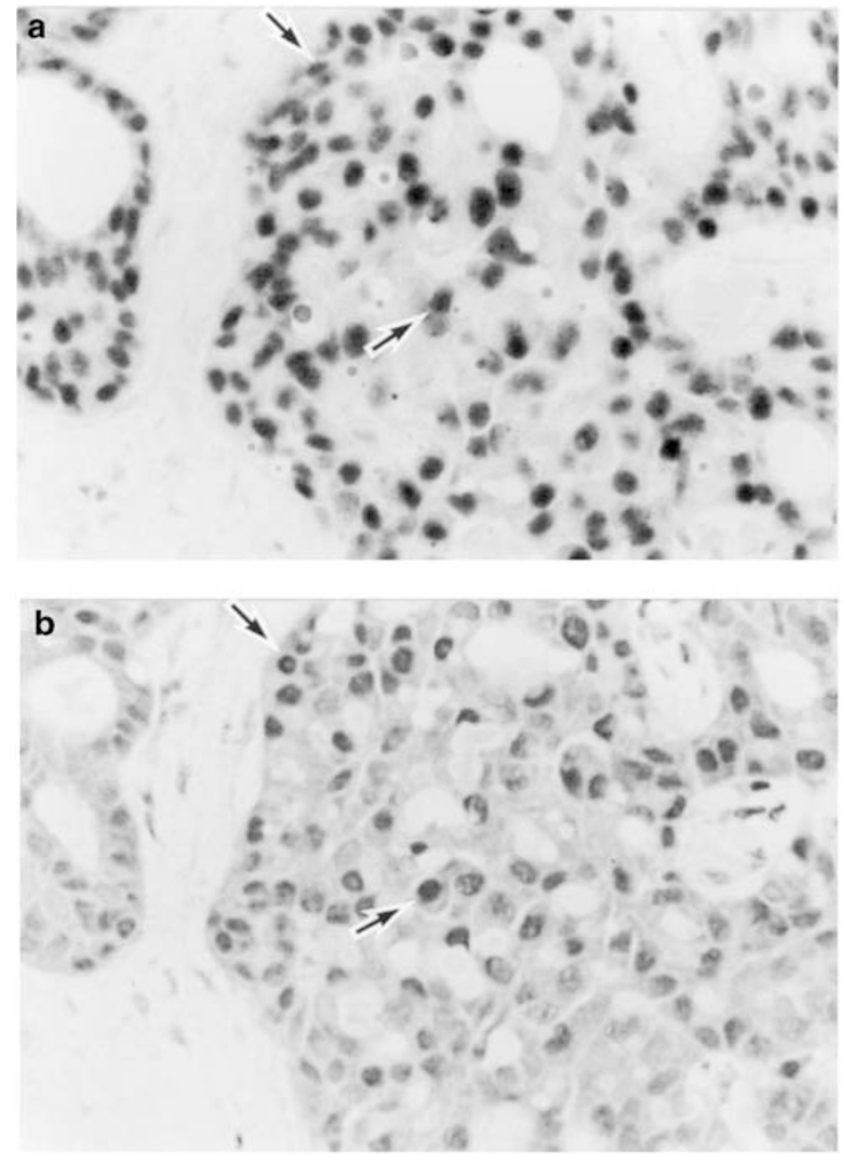

Figure 3 Immunohistochemistry for ER $\alpha$ and $\beta$ in adjacent sections of breast cancer. (a) ER $\alpha$ was detected in the nuclei of cancer cells. (b) ER $\beta$ was detected in the nuclei of cancer cells. Arrows $=$ positive cells. Magnification, $\times 100$.

ER $\beta$-negative, and 25 cases were both ER $\alpha$ - and $\beta$ positive. In both ER $\alpha$ - and $\beta$-positive cases, the distribution of ER $\alpha$ and ER $\beta$ largely coincided (Figure 3a and b).

As shown in Table 1, all of 19 KGF-positive cases were ER $\alpha$-positive, while all of 13 ER $\alpha$-negative cases were KGF-negative $(P<0.0001)$. On the other hand, 18 of 19 KGF-positive cases were ER $\beta$ positive, and five of six (83\%) ER $\beta$-negative cases were KGF-negative. Eighteen of 19 (95\%) KGFpositive cases were positive for both ER $\alpha$ and $\beta \quad(P<0.0001)$. To assess the direct relationship between KGF-positive cells and ER-positive cells, we performed double-staining for KGF and ERs. As shown in Figure $4 \mathrm{a}$ and $\mathrm{b}$, colocalization of ER $\alpha$ or $\beta$ and KGF in cancer cells was found, respectively. No significant correlation was found between ER expression and KGFR expression.

\section{Correlation between KGF and/or KGFR Expression and TUNEL Index}

TUNEL staining was performed to evaluate the correlation between KGF and/or KGFR expression
Table 1 Correlation between KGF expression and ER expression

\begin{tabular}{llrrrr}
\hline & & \multicolumn{2}{c}{ KGF expression } & \multirow{2}{*}{ P-value } \\
\cline { 2 - 4 } & & - & + & \\
\hline ER $\alpha$ expression & - & 13 & 0 & \\
ER $\beta$ expression & + & 10 & 19 & $<0.0001$ \\
Coexpression of ER $\alpha$ and $\beta$ & - & 5 & 1 & \\
& + & 18 & 18 & n.s. \\
& + & 7 & 18 & $<0.0001$
\end{tabular}

Correlation between KGF expression and ER $\alpha$ expression, ER $\beta$ expression, or coexpression of $\operatorname{ER} \alpha$ and $\beta$ was examined by $\chi^{2}$ analysis, respectively. A $P$-value less than 0.05 denoted the presence of a statistically significant correlation.
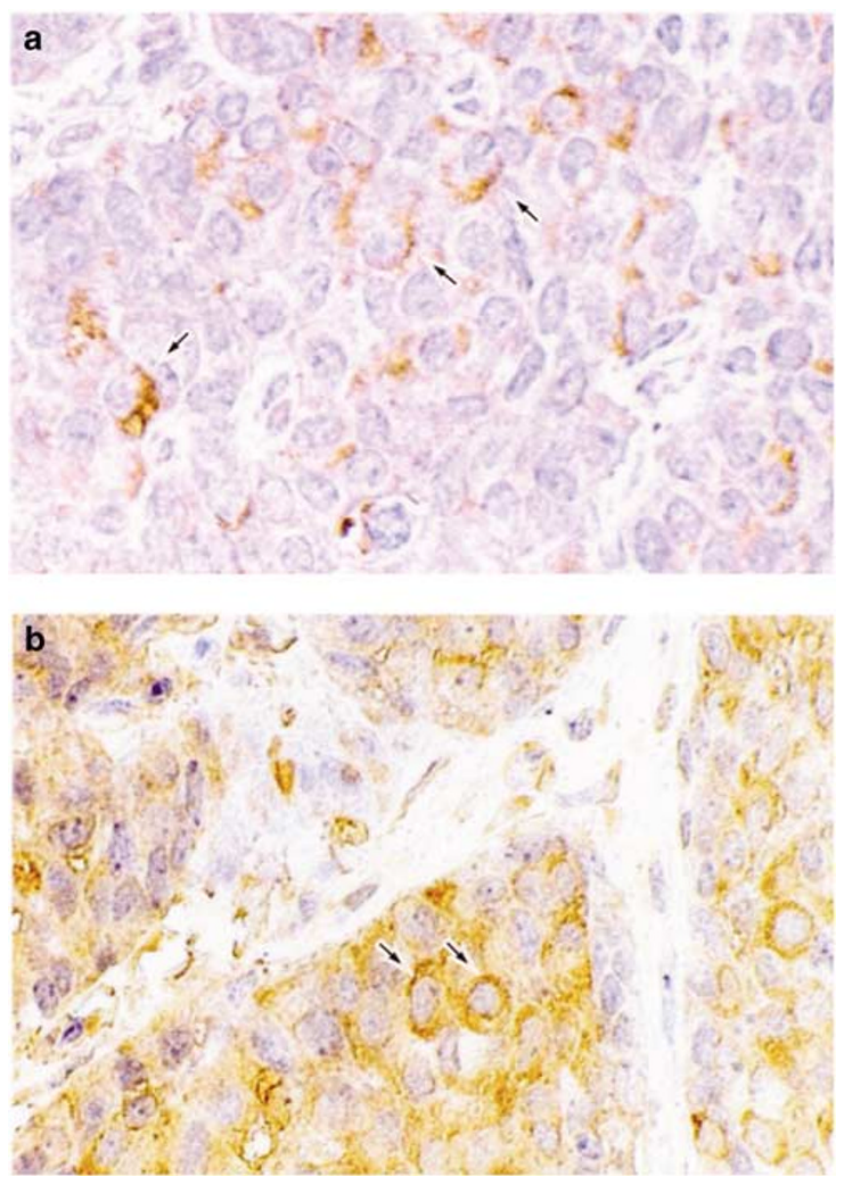

Figure 4 Double-staining for ERs and KGF in breast cancer tissue. (a) Double-staining for ER $\alpha$ (blue) and KGF (brown). (b) Doublestaining for ER $\beta$ (blue) and KGF (brown). ER $\alpha$ (a) and $\beta$ (b) was detected in the nuclei of cancer cells, and $\operatorname{KGF}(\mathbf{a}, \mathbf{b})$ was detected in the cytoplasm of cancer cells. Colocalization of ER $\alpha$ and KGF (a) and colocalization of ER $\beta$ and KGF (b) in cancer cells was observed (arrows). Magnification, $\times 200$.

and the frequency of apoptosis. As shown in Figure 5 , the percentage of TUNEL-positive cells of both KGF- and KGFR-positive cases was $1.0 \pm 0.9 \%$, which was significantly lower than that of other combinations such as both KGF- and KGFRnegative $(3.8 \pm 2.4 \%, P<0.05)$, KGF-negative, but 


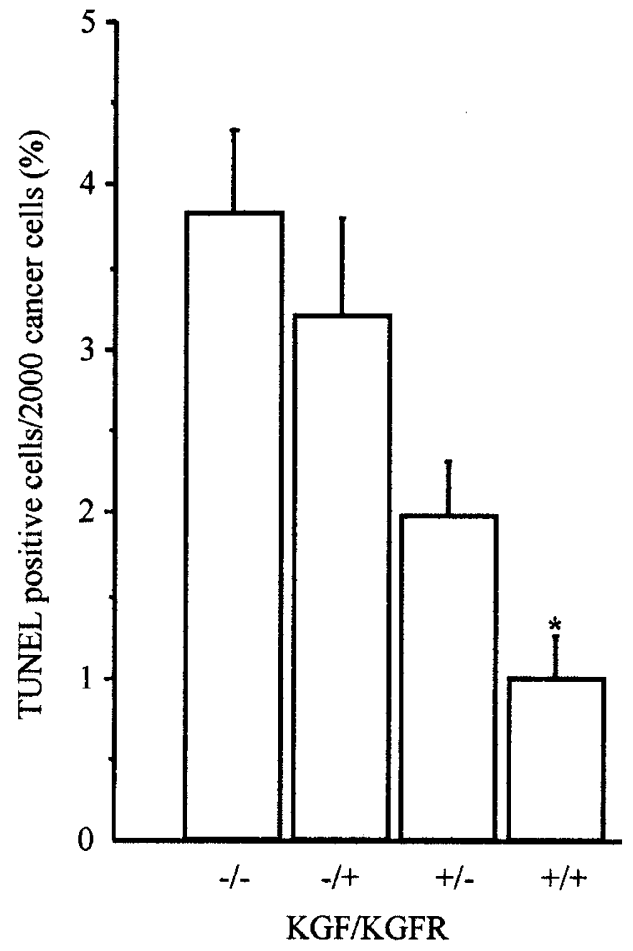

Figure 5 Correlation between TUNEL index and expression of KGF and KGFR in breast cancer tissues. Data are mean value of TUNEL index \pm s.d. ${ }^{*} P<0.05$.

KGFR-positive $(3.2 \pm 2.2 \%, P<0.05)$, KGF-positive, but KGFR-negative $(2.0 \pm 0.8 \%, P<0.05)$.

\section{Comparison between KGF and/or KGFR Expression and Cell Proliferation}

Ki-67 immunostaining was performed to evaluate the correlation between KGF and/or KGFR expression and the proliferative activity. The Ki-67 LI was $14.8 \pm 3.0 \%$ for both KGF- and KGFR-negative cases, $15.3 \pm 8.7 \%$ for KGF-negative but KGFR-positive cases, $12.1 \pm 4.3 \%$ for KGF-positive but KGFRnegative cases, and $11.3 \pm 6.0 \%$ for both KGF- and KGFR-positive cases. No correlation was found between the expression of KGF and/or KGFR and Ki-67 LI.

\section{Relationship between ER $\alpha$ and KGF Expression in Breast Cancer Cell Lines}

To assess whether KGF expression is associated with ER $\alpha$ expression, ER $\alpha$-positive and negative human breast cancer cell lines were incubated in the presence or absence of $10 \mathrm{nM} 17 \beta$-estradiol, and then KGF expression was examined by immunohistochemistry (Figure 6). In ER $\alpha$-negative SK-BR-3 (Figure 6a and b) and MDA-MB-231 (data not shown) cells, KGF was not detected irrespective of the presence of $17 \beta$-estradiol. On the other hand, in ER $\alpha$-positive MCF7 (Figure 6c and d) and ZR-75-1 (data not shown) cells, KGF was detected similarly in both conditions of $17 \beta$-estradiol.

\section{Effect of KGF upon the Induction of Apoptosis in Breast Cancer Cell Lines Treated with Anticancer Drugs}

As we confirmed the expression of KGFR protein by immunohistochemistry in MCF7 cells (data not shown), in which the expression of KGFR mRNA was reported, ${ }^{41,42}$ we conducted in vitro experiments to investigate the effect of KGF upon cell kinetics of MCF7 cells. When we counted the cell number in the presence or absence of $10 \mathrm{ng} / \mathrm{ml} \mathrm{KGF}$, no changes in the growth were observed (data not shown). However, when the cells were treated with $500 \mu \mathrm{g} / \mathrm{ml}$ cyclophosphamide or $25 \mu \mathrm{g} / \mathrm{ml}$ 5 -fluorouracil in the presence or absence of $10 \mathrm{ng} / \mathrm{ml} \mathrm{KGF}$ and the number of cells with nuclear fragmentation was counted after Hoechst 33342 staining, the frequency of cells with fragmented nuclei was dramatically decreased in the presence of KGF; 64 and $57 \%$ inhibition of the nuclear fragmentation were found in the case of cyclophosphamide and 5-fluorouracil, respectively, as shown in Figure 7.

\section{Discussion}

In the present study, we first investigated the expression of KGF and KGFR in human breast cancers at the levels of mRNA and protein, by means of in situ hybridization and immunohistochemistry, respectively. We then attempted to correlate the expression of these molecules with various parameters such as ER $\alpha$ and $\beta$, Ki-67 LI, and TUNEL index. Consequently, we detected the expression of KGF in breast cancer cells as well as stromal cells, while KGFR was expressed exclusively in the cancer cells.

KGF is considered to be expressed exclusively in stromal cells, and not epithelial cells. ${ }^{14,15}$ Indeed, no expression of KGF was detected in normal mammary epithelial cells. In the present study, however, we found for the first time that breast cancer cells expressed KGF in $45 \%$ of cases. Since breast cancer cells expressed KGFR in more than $50 \%$ of patients, we could assume the formation of autocrine and/or paracrine loops of KGF and KGFR within the cancer tissues. KGF was also detected in ovarian cancer cells, and a possible autocrine action of KGF and KGFR has been implicated in ovarian cancer development. ${ }^{43}$ Therefore, the expression of KGF in epithelial cells may not be so unlikely, especially in malignancy.

KGF has been also recognized as a steroid hormone-dependent growth factor in various organs; in rat prostate gland, the expression of KGF mRNA is regulated by androgen, ${ }^{17}$ and in monkey uterus, KGF mRNA and protein expression 


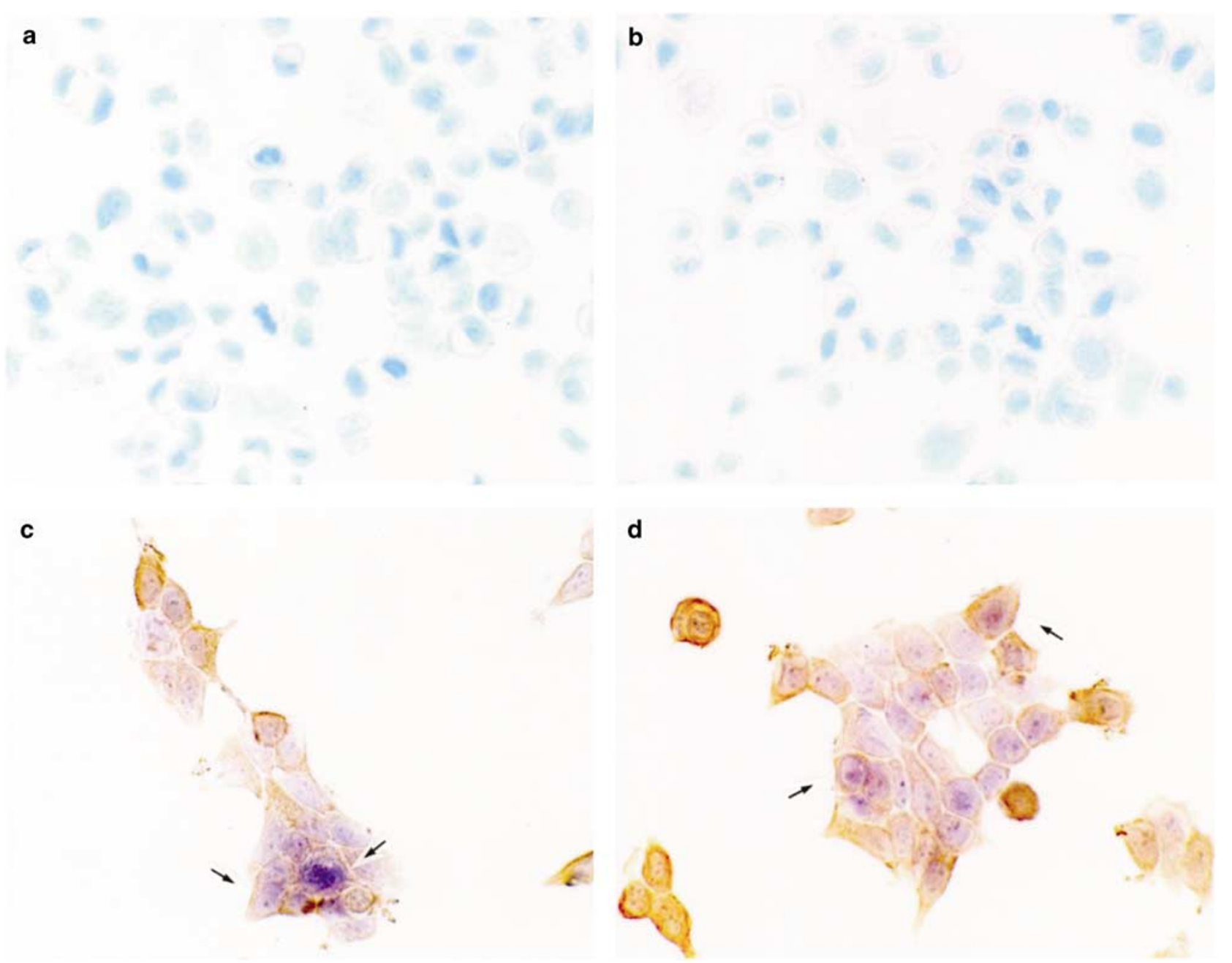

Figure 6 Immunohistochemistry for KGF in human breast cancer cell lines. (a and b) ER-negative SK-BR-3 incubated in the absence (a) or presence (b) of $10 \mathrm{nM} 17 \beta$-estradiol. KGF was negative in both situations. Nulcei were stained with methyl green. (c and d) Double staining for ER $\alpha$ and KGF in ER-positive MCF7 incubated in the absence (c) or presence (d) of $10 \mathrm{nM} 17 \beta$-estradiol. ER $\alpha$ (nuclei, blue) and KGF (cytoplasm, brown) were colocalized in both situations. Arrows = positive cells. Magnification, $\times 200$.

appears to be dependent upon progesterone. ${ }^{18}$ Estrogen-dependent elevation of KGF mRNA expression was reported in isolated stromal cells from human breast cancer in vitro ${ }^{20}$ and in mouse mammary gland in vivo. ${ }^{44}$ In the present study, KGF expression was tightly associated with ER $\alpha$ expression in surgical specimens of human breast cancer tissues, and KGF was expressed only in ER $\alpha$ positive human breast cancer cell lines, MCF7 and ZR-75-1. Although unexpectedly, the expression of KGF in these cells was not affected significantly by the presence or absence of estrogen, ER $\alpha$-dependent regulation of KGF expression may be in a ligandindependent manner. Indeed, estrogen-independent activation of ER by growth factors such as EGF ${ }^{45}$ and IGF- $1^{46}$ and by the elevation of CAMP $^{45,46}$ was already known. Considering that promoter of KGF gene harbors semi-palindromic consensus sequences of the estrogen responsive element, ${ }^{47}$ our present study showing coexpression of KGF and ER $\alpha$ in human breast cancer cells provides further evidence of the ER $\alpha$-dependent regulation of KGF expression.

In the present study, the coexpression of KGF and KGFR in breast cancer tissue was significantly correlated with a lower frequency of TUNELpositive cells. Moreover, KGF inhibited the induction of apoptosis by anticancer drugs in MCF7 cells in vitro. These results seem to indicate antiapoptotic effect of KGF in breast cancer cells. Antiapoptotic effect of KGF was previously reported in human keratinocytes, ${ }^{22}$ human prostate cancer cells, ${ }^{21}$ and intestinal epithelium of total parenteral nutrition model mouse. ${ }^{23}$ In human prostate cancer cells ${ }^{21}$ and mouse intestinal epithelium, ${ }^{23} \mathrm{Bcl}-2$ is implicated in antiapoptotic effect of KGF. In human breast cancer, Bcl-2 is suggested to inhibit apoptosis, and lower frequency of apoptosis is reported to be a better prognosis marker. ${ }^{48,49}$ In this context, KGF might inhibit apoptosis through the elevation of Bcl2 level in human breast cancer, and coexpression of KGF and KGFR could be correlated with a better 


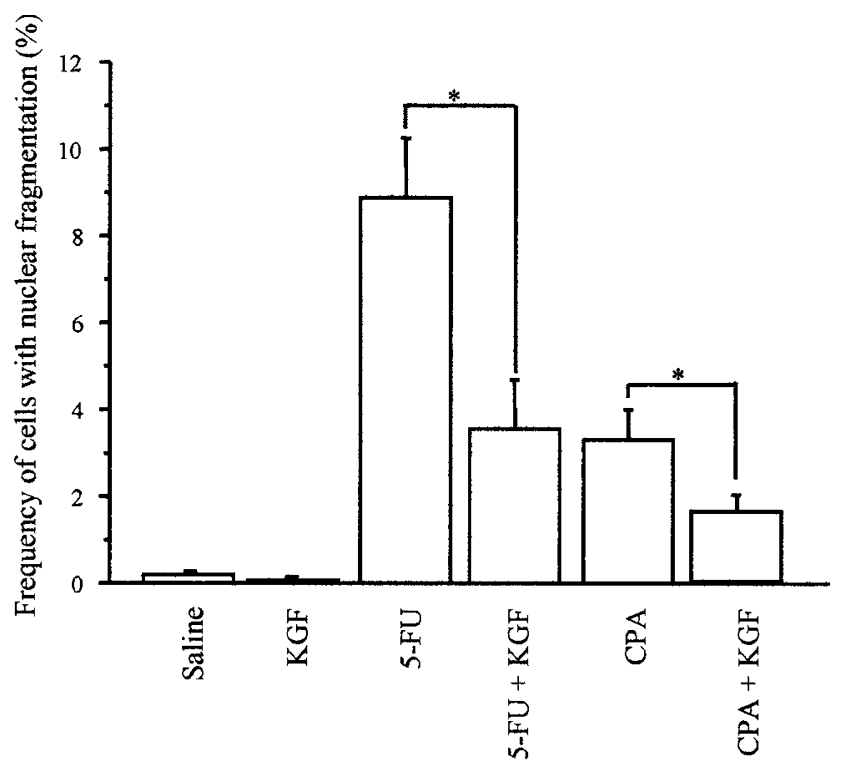

Figure 7 Frequency of cells with nuclear fragmentation in MCF7 treated with anticancer drugs and/or $10 \mathrm{ng} / \mathrm{ml} \mathrm{KGF}$. Data are given as the mean \pm s.d. from three independent experiments. ${ }^{*} P<0.05$. 5-FU $=5$-fluorouracil $(25 \mu \mathrm{g} / \mathrm{ml}) ; \mathrm{CPA}=$ cyclophosphamide $(500 \mu \mathrm{g} / \mathrm{ml})$.

prognosis, though the direct relationship between KGF expression and prognosis remains unclear at present.

In the present study, no correlation was found between coexpression of KGF and KGFR and Ki-67 $\mathrm{LI}$ in human breast cancer. In fact, it has been known that KGF induces cell differentiation and suppresses cell proliferation in some cases. For example, KGF is known to promote the differentiation of keratinocytes derived from human neonatal foreskin ${ }^{24,25}$ as well as human lung squamous cell carcinoma. ${ }^{26} \mathrm{In}$ human salivary gland tumors, loss of KGFR expression was observed in the process of malignant transformation..$^{50,51}$ Similarly, in prostate cancer, loss of KGFR expression was accompanied by the switch from androgen-sensitive, slow-growing tumors to androgen-insensitive, more aggressive tumors. ${ }^{52}$ Therefore, KGF may play a pivotal role in the regulation of cell kinetics.

In conclusion, we have confirmed the expression of KGF and KGFR in human breast cancer cells at the level of both mRNA and protein, and have found a close association of KGF expression with the presence of $E R \alpha$. And we have further indicated that KGF may play an inhibitory role in the induction of breast cancer cell apoptosis, raising a possibility that KGF may give resistancy against anticancer drugs to the cancer cells.

\section{Acknowledgements}

We thank Ms Miho Kawakatsu (Division of Histology and Cell Biology, Department of Developmental and Reconstructive Medicine, Nagasaki University Graduate School of Biomedical Science) for her help throughout in vitro experiments, and Dr Hirofumi Kubota (Second Department of Surgery, Shimane Medical University) for preparing the paraffin blocks used in the present studies.

This study was supported in part by a Grant-inAid for Scientific Research from the Japanese Ministry of Education, Science, Sports, and Culture (Nos. 1247003, 15390058, and 16659047 to T Koji) and by a grant from the Japanese Environment Agency (to T Koji).

\section{References}

1 Henderson BE, Ross R, Bernstein L. Estrogens as a cause of human cancer: the Richard and Hinda Rosenthal Foundation award lecture. Cancer Res 1988;48:246-253.

2 Katzenellenbogen BS, Kendra KL, Norman MJ, et al. Proliferation, hormonal responsiveness, and estrogen receptor content of MCF-7 human breast cancer cells grown in the short-term and long-term absence of estrogens. Cancer Res 1987;47:4355-4360.

3 Osborne CK, Hobbs K, Clark GM. Effect of estrogens and antiestrogens on growth of human breast cancer cells in athymic nude mice. Cancer Res 1985;45: 584-590.

4 Beato M. Gene regulation by steroid hormones. Cell 1989;56:335-344.

5 Paech K, Webb P, Kuiper G, et al. Differential ligand activation of estrogen receptors ER $\alpha$ and ER $\beta$ at AP-1 sites. Science 1997;277:1508-1510.

6 Fuqua SA, Schiff R, Parra I, et al. Estrogen receptor beta protein in human breast cancer: correlation with clinical tumor parameters. Cancer Res 2003;63: 2434-2439.

7 Jarvinen T, Pelto-Huikko M, Holli K, et al. Estrogen receptor $\beta$ is coexpressed with ER $\alpha$ and $\mathrm{PR}$ and associated with nodal status, grade, and proliferation rate in breast cancer. Am J Pathol 2000;156:29-35.

8 Speirs V, Malone C, Walton DS, et al. Increased expression of estrogen receptor $\beta$ mRNA in tamoxifenresistant breast cancer patients. Cancer Res 1999;59: 5421-5424.

9 Bates SE, Davidson NE, Valverius EM, et al. Expression of transforming growth factor- $\alpha$ and its messenger ribonucleic acid in human breast cancer: its regulation by estrogen and its possible functional significance. Mol Endocrinol 1988;2:543-555.

10 El-Ashry D, Chrysogelos S, Lippman ME, et al. Estrogen induction of TGF- $\alpha$ is mediated by an estrogen response element composed of two imperfect palindromes. J Steroid Biochem Mol Biol 1996;59: 261-269.

11 Hynes NE, Stern DF. The biology of erbB-2/neu/HER-2 and its role in cancer. Biochem Biophys Acta 1994; 1198:165-184.

12 Read LD, Keith Jr D, Slamon DJ, et al. Hormonal mudulation of HER-2/neu protooncogene messenger ribonucleic acid and p185 protein expression in human breast cancer cell lines. Cancer Res 1990; 50:3947-3951. 
13 Russel KS, Hung MC. Transcriptional repression of the neu protooncogene by estrogen stimulated estrogen receptor. Cancer Res 1992;52:6624-6629.

14 Rubin JS, Osada H, Finch PW, et al. Purification and characterization of a newly identified growth factor specific for epithelial cells. Proc Natl Acad Sci USA 1989;86:802-806.

15 Finch PW, Rubin JS, Miki T, et al. Human KGF is FGFrelated with properties of a paracrine effector of epithelial cell growth. Science 1989;245:752-755.

16 Miki T, Bottaro DP, Fleming TP, et al. Determination of ligand-binding specificity by alternative splicing: two distinct growth factor receptors encoded by a single gene. Proc Natl Acad Sci USA 1992;89:246-250.

17 Yan G, Fukabori Y, Nikolaropoulos S, et al. Heparinbinding keratinocyte growth factor is a candidate stromal to epithelial cell andromedin. Mol Endocrinol 1992;6:2123-2128.

18 Koji T, Chedid M, Rubin JS, et al. Progesteronedependent expression of keratinocyte growth factor mRNA in stromal cells of the primate endometrium: keratinocyte growth factor as a progestomedin. J Cell Biol 1994;125:393-401.

19 Bansal GS, Cox HC, Marsh S, et al. Expression of keratinocyte growth factor and its receptor in human breast cancer. Br J Cancer 1996;75:1567-1574.

20 Zhang Y, Sugimoto Y, Kulp SK, et al. Estrogen-induced keratinocyte growth factor mRNA expression in normal and cancerous human breast cells. Oncol Rep 1998;5:577-583.

21 Crescioli C, Maggi M, Luconi $\mathrm{M}$, et al. Vitamin $\mathrm{D}_{3}$ analogue inhibits keratinocyte growth factor signaling and induces apoptosis in human prostate cancer cells. Prostate 2002;50:15-26.

22 Hines MD, Allen-Hoffman BL. Keratinocyte growth factor inhibits cross-linked envelope formation and nucleosomal fragmentation in cultured human keratinocytes. J Biol Chem 1996;271:6245-6251.

23 Wildhaber BE, Yang H, Teitelbaum DH. Keratinocyte growth factor decreases total parenteral nutritioninduced apoptosis in mouse intestinal epithelium via bcl-2. J Pediatr Surg 2003;38:92-96.

24 Marchese C, Rubin J, Ron D, et al. Human keratinocyte growth factor activity on proliferation and differentiation of human keratinocytes: differentiation response distinguishes KGF from EGF family. J Cell Physiol 1990;144:326-332.

25 Marchese C, Sorice M, Stefano C, et al. Modulation of keratinocyte growth factor receptor expression in human cultured keratinocytes. Cell Growth Differ 1997;8:989-997.

26 Yamayoshi T, Nagayasu T, Matsumoto K, et al. Expression of keratinocyte growth factor/fibroblast growth factor-7 and its receptor in human lung cancer: correlation with tumor proliferative activity and patient prognosis. J Pathol 2004, in press.

27 Hovey RC, Davey HW, Vonderhaar BK, et al. Paracrine action of keratinocyte growth factor (KGF) during ruminant mammogenesis. Mol Cell Endocrinol 2001; 181:47-56.

28 Yoshii A, Koji T, Ohsawa N, et al. In situ localization of ribosomal RNAs is a reliable reference for hybridizable RNA in tissue sections. J Histochem Cytochem 1995; 43:321-328.

29 Yamamoto-Fukuda T, Aoki D, Hishikawa Y, et al. Possible involvement of keratinocyte growth factor and its receptor in enhanced epithelial-cell proliferation and acquired recurrence of middle-ear cholesteatoma. Lab Invest 2003;123:123-136.

30 Nishihara E, Nagayama Y, Inoue S, et al. Ontogenic changes in the expression of estrogen receptor $\alpha$ and $\beta$ in rat pituitary gland detected by immunohistochemistry. Endocrinology 2000;141:615-620.

31 Tsurusaki T, Aoki D, Kanetake $\mathrm{H}$, et al. Zonedependent expression of estrogen receptor $\alpha$ and $\beta$ in human benign prostatic hyperplasia. J Clin Endocrinol Metab 2003;88:1333-1340.

32 Hakuno N, Koji T, Yano T, et al. Fas/APO-1/CD95 system as a mediator of granulosa cell apoptosis in ovarian follicle atresia. Endocrinology 1996;137: 1938-1948.

33 Graham Jr RC, Karnovsky MJ. The early stages of absorption of injected horseradish peroxidase in the proximal tubules of mouse kidney: ultrastructural cytochemistry by a new technique. J Histochem Cytochem 1965;14:291-302.

34 Adams JC. Heavy metal intensification of DAB-based HRP reaction product. Histochem Cytochem 1981; 29:775.

35 Elias JM. A rapid, sensitive myeloperoxidase stain using 4-chloro-1 naphthol. Am J Clin Pathol 1980; 73:797-799.

36 Koji T, Nakane PK. Recent advances in molecular histochemical techniques: in situ hybridization and southwestern histochemistry. J Electron Microsc 1996; 45:119-127.

37 Hishikawa Y, Koji T, Dhar DK, et al. Metallothionein expression correlates with metastatic and proliferative potential in squamous cell carcinoma of the oesophagus. Br J Cancer 1999;81:712-720.

38 Koji T, Brenner RM. Localization of estrogen receptor messenger ribonucleic acid in rhesus monkey uterus by nonradioactive in situ hybridization with digoxigenin-labeled oligodeoxynucleotides. Endocrinology 1993;132:382-392.

39 Gavrieli Y, Sherman Y, Ben-Sasson SA. Identification of programmed cell death in situ via specific labeling of nuclear DNA fragmentation. J Cell Biol 1992;119:493-501.

40 Schulte EK, Lyon HO, Hoyer PE. Simultaneous quantification of DNA and RNA in tissue sections. A comparative analysis of the methyl green-pyronin technique with the gallocyanin chromalum and Feulgen procedures using image cytometry. Histochem J 1992;24:305-310.

41 Zang X, Learner ML, Brackett DJ, et al. KGF-induced gene expression in MCF-7 cells using cDNA expression arrays. Breast Cancer Res Treat 2000;64:110.

42 Zang XP, Lerner MR, Dunn ST, et al. Antisense KGFR oligonucleotide inhibition of KGF-induced motility in breast cancer cells. Anticancer Res 2003;23:4913-4919.

43 Parrott JA, Kim G, Mosher R, et al. Expression and action of keratinocyte growth factor (KGF) in normal ovarian surface epithelium and ovarian cancer. Mol Cell Endocrinol 2000;167:77-87.

44 Pedchenko VK, Imagawa W. Estrogen treatment in vivo increases keratinocyte growth factor expression in the mammary gland. J Endocrinol 2000;165:39-49.

45 El-Tanani MKK, Green CD. Two separate mechanisms for ligand-independent activation of the estrogen receptor. Mol Endocrinol 1997;11:928-937.

46 Aronica SM, Katzenellenbogen BS. Stimulation of estrogen receptor-mediated transcription and alteration in the phosphorylation state of the rat uterine 
estrogen receptor by estrogen, cyclic adenosine monophosphate, and insulin-like growth factor-I. Mol Endocrinol 1993;7:743-752.

47 Finch PW, Lengel C, Chedid M. Cloning and characterization of the promoter region of the human keratinocyte growth factor gene. J Biol Chem 1995; 270:11230-11237.

48 Lipponen P, Aaltomaa S, Kosma VM, et al. Apoptosis in breast cancer as related to histopathological characteristics and prognosis. Eur J Cancer 1994;30A: 2068-2073.

49 Vakkala M, Lahteenmaki K, Raunio H, et al. Apoptosis during breast carcinoma progression. Clin Cancer Res 1999;5:319-324.
50 Tanaka Y, Sakamoto A, Yan Z, et al. Molecular diagnosis of human salivary gland tumors by differential expression of fibroblast growth factor receptor genes. Tiss Cult Res Commun 1997;16: 207-213.

51 Zhang Y, Wang H, Toratani S, et al. Growth inhibition by keratinocyte growth factor receptor of human salivary adenocarcinoma cells through induction of differentiation and apoptosis. Proc Natl Acad Sci USA 2001;98:11336-11340.

52 Carstens RP, Eaton JV, Krigman HR, et al. Alternative splicing of fibroblast growth factor receptor 2 (FGF-R2) in human prostate cancer. Oncogene 1997; 15:3059-3065. 